University of Wollongong

Research Online

Faculty of Informatics - Papers (Archive)

Faculty of Engineering and Information

Sciences

$12-9-2004$

\title{
Primary and secondary indices for power quality (PQ) survey reporting
}

V. J. Gosbell

University of Wollongong, vgosbell@uow.edu.au

S. Perera

University of Wollongong, sarath@uow.edu.au

Robert A. Barr

University of Wollongong, rbarr@uow.edu.au

Alex Baitch

University of Wollongong, abaitch@uow.edu.au

Follow this and additional works at: https://ro.uow.edu.au/infopapers

Part of the Physical Sciences and Mathematics Commons

\section{Recommended Citation}

Gosbell, V. J.; Perera, S.; Barr, Robert A.; and Baitch, Alex: Primary and secondary indices for power quality (PQ) survey reporting 2004.

https://ro.uow.edu.au/infopapers/141

Research Online is the open access institutional repository for the University of Wollongong. For further information contact the UOW Library: research-pubs@uow.edu.au 


\title{
Primary and secondary indices for power quality (PQ) survey reporting
}

\author{
Abstract \\ Routine monitoring involves many PQ monitors at fixed sites with readings able to be interrogated \\ remotely and downloaded to a central database. The amount of data for one year is large, and innovative \\ methods are needed to ensure that it can give useful insights. Primary indices are proposed to show \\ whether a site is acceptable to specified standards and are mainly based on $95 \%$ values. Secondary \\ indices are proposed to give additional insights. For variations, indices are proposed to give a measure of \\ the impact on customer equipment beyond that incorporated in standards. Sag secondary indices are \\ defined to give insights as to the factors responsible for poor sag performance. Indicative maximum \\ acceptable values are given for secondary indices based on a recent Australian survey of several \\ distributors. \\ Disciplines \\ Physical Sciences and Mathematics \\ Publication Details \\ This article originally appeared as: Gosbell, VJ, Perera, S, Barr, R \& Baitch, A, Primary and secondary \\ indices for power quality (PQ) survey reporting, 11th International Conference on Harmonics and Quality \\ of Power, 12-15 September 2004, 419-424. Copyright IEEE 2004.
}




\title{
Primary and Secondary Indices for Power Quality (PQ) Survey Reporting
}

\author{
V.J. Gosbell, Member IEEE, S. Perera, Member IEEE, R. Barr, Member IEEE, A. Baitch, Member IEEE
}

\begin{abstract}
Routine monitoring involves many $P Q$ monitors at fixed sites with readings able to be interrogated remotely and downloaded to a central database. The amount of data for one year is large, and innovative methods are needed to ensure that it can give useful insights. Primary indices are proposed to show whether a site is acceptable to specified standards and are mainly based on $95 \%$ values. Secondary indices are proposed to give additional insights. For Variations, indices are proposed to give a measure of the impact on customer equipment beyond that incorporated in standards. Sag secondary indices are defined to give insights as to the factors responsible for poor sag performance. Indicative maximum acceptable values are given for secondary indices based on a recent Australian survey of several distributors.
\end{abstract}

Index Terms- Power quality survey, index.

\section{INTRODUCTION}

$\mathrm{D}$ istribution utilities are increasingly taking a pro-active role in the routine measurement of $P Q$ levels on their networks. Routine monitoring involves PQ monitors at many fixed sites able to be interrogated remotely and downloaded to a central database. With some tens of sites and many readings every 10 minutes, the amount of data for one year is large, and innovative methods are needed to ensure that it can give useful insights. The authors are associated with routine distribution over several utilities across the east coast of Australia, recovering $2 \mathrm{~GB}$ of data in one year. As a result of this project, the procedures discussed in this paper were developed.

PQ disturbances can be classified into two main types requiring different analysis procedures

A. Variations (or continuous disturbances): present in each cycle of the waveform, for example voltage level, unbalance, flicker, harmonics. These are subject to well defined standards using statistical parameters such as $95 \%, 99 \%$ and $100 \%$ values.

$B$. Events (or discrete disturbances): resulting from a short term incident, such as sags, swells, impulsive and oscillatory transients. There are no widely accepted standards yet for these quantities.

V.J. Gosbell and S. Perera are with the Integral Energy Power Quality Centre, School of Electrical Computer \& Telecommunications Engineering, University of Wollongong, NSW 2522, Australia.

R.Bart is with Power Consulting PL, Australia

A. Baitch is with BES (Aust) PL. Baulkham Hills, NSW 2153, Australia

(Corresponding E-mails: v.gosbell@uow.edu.au, s.perera@uow.edu.au, r.barr@.au, baitcl@besaust.com.au).
In Australia at present, the disturbances of most concern are

- Variations: voltage (long term voltage variation), unbalance, harmonics (with flicker of interest at some sites).

- Events: sags.

In considering how to summarise survey data, use is commonly made of summary parameters or indices. The objectives of the indices need to be carefully thought out before deciding on a particular data analysis procedure. In the routine $P Q$ survey of distribution systems, some key objectives for Variations are

(i) Summarise the level of PQ disturbances at the site

(ii) Allow the sites to be ranked so that those most deserving of remedial work can be immediately identified

(iii) Show if a site is acceptable based on national standards or regulator codes

(iv) Indicate whether the trends at a particular site are normal or abnormal to flag possible problems such as atypical load behaviour, voltage regulator malfunction, inappropriate planning assumptions.

Objectives (i)-(iii) can be met by indices based on the parameters used in standards. In the case of harmonics and flicker, following $[1,2]$, the $95 \%$ value of 10 minute readings might be chosen. Such indices are clearly the most important because of the importance of Objective (iii) and we shall call standards-based indices "Primary Indices" in this paper.

However, utilities are now asking for more than just that they have met the standards. Meeting Objective (iv) may enable a utility to determine problem situations before standards are exceeded and some new approach is required. Indices of this type, that is non-standards based, we called "Secondary Indices". Their value is purely internal to the utility for diagnostic purposes and does indicate whether standards have been met or not.

The paper will treat primary and secondary indices adopted in the Australian long term national PQ survey programme.

\section{I1. PRIMARY INDICES}

It is essential that consistent measurement practices are adopted so that sites can be compared across utilities and utilities be benchmarked against each other. We shall summarise some established aspects given in [3]. The basic measurement window for Variations is 10 cycles. Values obtained over 3 seconds can be combined by an rms averaging 
process to give very short time values. Their values over 10 minute intervals can be further combined to give short time values. These are the values that are the starting point for most $P Q$ reporting considerations.

In summarising time-varying Variation values over long time intervals such as a day or week, it is natural to look at statistical values such as $100 \%, 95 \%$ or simple averages. $100 \%$ values have two problems for the purposes of characterising a site

- They may occur for only very short times and be unrepresentative of values occurring for most of the time

- Their occurrence is due to a chance combination of factors that may not occur again for many weeks. Hence the $100 \%$ value measured in one week can be significantly different to that of the following week. This makes them unsuitable for giving a consistent and repeatable characterisation of a site.

For many purposes, $95 \%$ values of 10 minute readings have been accepted in several standards as the most suitable. There is then the question as to whether daily or weekly values should be used. Weekly values are most often called up by standards. However, there is the possibility that values significantly higher than the $95 \%$ value can occur for up to $5 \%$ of a week, that is for as much as 8.4 hours continuously. To avoid this, it is recommended to take the $95 \%$ value over a day. Since the week is the fundamental cycle for power system demand, we recommend that a suitable statistic is the maximum, over the week, of the daily $95 \%$ values. We shall simply speak of $95 \%$ values below without distinguishing between the two periods over which they might be taken.

The determination of some site primary indices will be discussed below. Unbalance is a simple case to begin with for two reasons

(i) There is only one value across the three phases (unlike voltage, harmonics)

(ii) Its preferred value is zero, with larger values always being worse (unlike voltage)

\section{A. Unbalance}

According to a strict reading of [3], unbalance should be determined every 10 cycles from corresponding voltage values and the values combined to give 10 minute values. It can be found from the sequence components or directly from the measured values as described in [4]. The same reference also discusses the errors introduced if line-neutral values are used instead of line-line values and if 10 minute voltage values are used instead of 10 cycle values.

Following the practices adopted for harmonics and flicker standards $[1,2]$, a value for a given week can be found from either the $95 \%$ value of 10 minute readings over each day or the week. Note that this is consistent with how unbalance is described in [5]. Where several weeks' data is available, the index for each week can be determined and the maximum over the weeks recorded to characterize the site. The individual weekly values might be retained for trend analysis but this aspect is followed up here.

\section{B. Harmonics}

For each phase, THD and individual harmonics up to about the $40^{\text {th }}$ are measured [1]. For each quantity we can take the $95 \%$ value as discussed previously, and then find the maximum over the three phases. Where the values across the three phases differ by an unexpected amount, this might be flagged for further investigation.

In Australia, it is common at this stage to concentrate only on THD and the $5^{\text {th }}$ harmonic at most distribution sites as all other harmonic components are small. THD then becomes a single indicator of the overall harmonic state of a site. Although the neglect of all other harmonics is a major assumption, its validity can be checked by means of a Harmonic Inclusiveness Index as described later.

Where other harmonic components are important, it is still possible to obtain a single meaningful harmonic index by a two step process called Normalisation and Consolidation as described in [6]. Briefly, the THD and the individual harmonic indices, found as described above, are each divided by its corresponding limit and the maximum value taken. If the overall harmonic index is 0.6 , for example, this reveals that the worst harmonic component at the site is $60 \%$ of the limit and gives a direct indication of the headroom for further harmonic increase.

\section{Voltage}

Voltage gives an initial difficulty for index purposes in that its ideal value is non-zero. This can be overcome by the concept of Absolute Voltage Deviation (AVD), defined as the absolute difference between the measured voltage and the voltage in the middle of the desired range [7]. This quantity can conveniently given as the percentage of the nominal voltage. An example may make this clear. Suppose that a reading of $242.2 \mathrm{~V}$ is obtained for a nominal $230 \mathrm{~V}-2 \% /+10 \%$ system (common in Australia at LV for a couple of years). The middle-of the-range is $230+4 \%$ or $239.2 \mathrm{~V}$. The absolute voltage deviation is then $3 \mathrm{~V}$ or $1.3 \%$ of $230 \mathrm{~V}$. This quantity is related to how voltage quality is specified in [5].

The $95 \%$ value of this quantity may then be found as for harmonic quantities, with the maximum value over the three phases being retained to characterize the week. There should be no need to flag large discrepancies across the three phases since this should be signified by the Unbalance Index.

\section{Sags}

There is no satisfactory international standard leading to the determination of a single index to characterise a site over a survey period. The principles by which one number can be found are given in [8].

A particular proposal has been given in detail in [9]. The starting point is the original CBEMA curve which is plotted on horizontal and vertical axes of sag duration and retained voltage. The display of a particular sag on this set of axes takes account of phase and time aggregation as well discussed in the literature. The lower CBEMA curve is taken to be a contour of equal customer complaint for an ensemble of "typical customers" and all sags lying on this contour are given a CBEMA number of 1 . This contour is scaled to give a number of other contours as shown in Fig. 1 where, for 
example, a sag having parameters $0.1 \mathrm{sec}$ duration and $60 \%$ retained voltage can be seen to have a CBEMA number of 2 . A suitable numerical expression for the CBEMA curve is given in [9] making the whole process simple to implement by computer. A Sag Severity Index is defined as equal to the CBEMA number but with two minor modifications as detailed in [9]. One is an upper limit as it is assumed that all sags exceeding $0 \%$ retained voltage and $3 \mathrm{sec}$ duration will have the same effect of maximum customer complaints. Another modification is to reduce the sensitivity of the index for sags near $90 \%$ retained voltages to allow for the inevitable slight differences in monitor threshold settings.

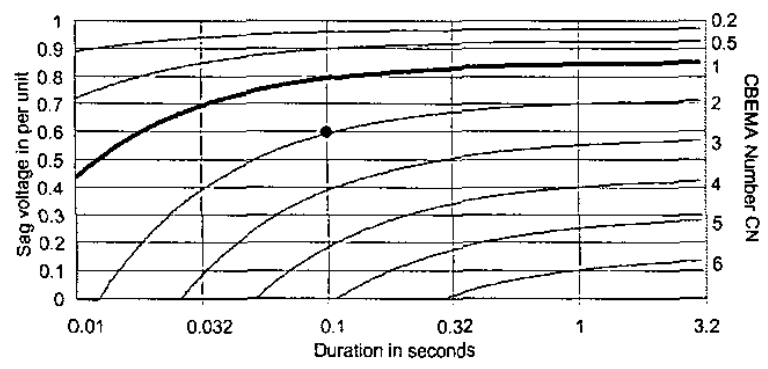

Fig. 1 Sag contours for determining sag severity

It is usual in many discussions of sag characterisation to combine unbalanced sags by a process of "phase aggregation", leading to the three phase sag being characterised by the most severely affected phase. This fails to recognise that the "equivalent" balanced three phase sag is more severe than the original unbalanced one for both three phase and single phase loads. We recommend that the average sag severity index across the three phases be taken for characterising a single sag. Time aggregation may still be applied as described in the literature for other sag characterisation schemes.

The sag index for a survey period is the sum of all the sag severity indices as determined by the above procedure. To allow consistent comparisons between sites, this index is scaled to an annual reporting period.

\section{SECONDARY INDICES}

Power quality surveys give rise to an enormous amount of data and it would be a pity to simply concentrate on those indices which relate to conformance with standards. There is also information which relates to the design practices of the utility or the operation of equipment. For example, sites can give rise to the same $95 \%$ value of unbalance index in different ways. For the $5 \%$ of the time which is unrepresented in the $95 \%$ statistic, unbalance values might vary between sites in significantly different ways. This paper proposes a method for representing this behaviour by an index. From a survey over many sites, we have found preliminary values for the normal range for these new indices, and sites lying outside this range can be considered for further investigation.

Particular aims are slightly different for each disturbance type as shown by the following discussion. For Variations, a secondary index is determined to measure the impact of extreme values on customer equipment according to a proposed mathematical model. For harmonics, where only a few harmonic components are recorded, an additional index is defined to indicate if the neglected harmonics are indeed negligible. For sags, the interest is in identifying some of the factors which might have led to a high sag index.

Fig. 2 shows a variation in a quantity such as Unbalance or Absolute Voltage Deviation. The secondary indices proposed here are attempts to characterise the impact of high values of the Variations on customer equipment. The following pragmatic assumptions are made in order to determine an algorithm.

- The limit represents values below which equipment can operate indefinitely without problems.

- When it exceeds the limit, the impact increases faster than linearly than the exceedance - a square law relationship has been assumed.

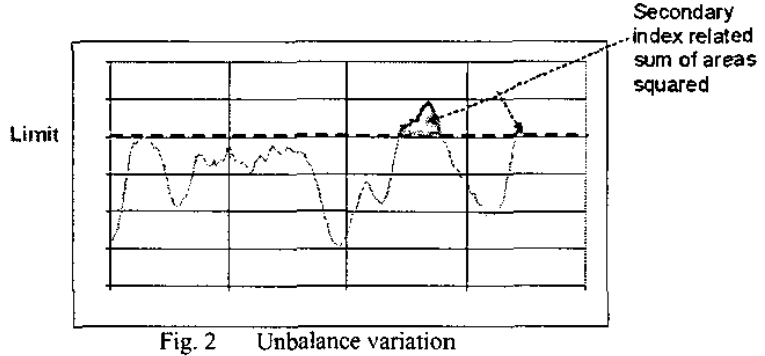

The total impact is proportional to the sum of the squares of the exceedances, which is related to the sum of the squares of the marked areas in Fig. 2. To provide an index in a form which is more comprehensible, the sum is divided by the survey period and the square root is taken. A physical interpretation of the index is the equivalent constant margin over the limit to give the same impact as the original waveform.

This concept is very similar to that of standard deviation, except that values are now measured with the limit value as datum, rather than zero, and negative values are ignored. The proposed concept has the advantage that, at a site where the limit is never exceeded, the secondary index is zero. An . inconvenience of this definition is that if the limit is changed, the index needs to be recalculated from the original complete set of measurement values.

\section{A. Unbalance}

The secondary index proposed for Unbalance is the Unbalance-over-Limit index defined as follows in a 2-step process

Step (i): Unbalance-over-Limit (UoL)

Let $V_{U} F_{\max }$ be maximum acceptable unbalance

If $V U F>V F_{\max } \quad U o L=\left(V U F-V F_{m a x}\right)$

If $\mathrm{VUF}<\mathrm{VUF}_{\max } \quad \mathrm{UoL}=0$

Step (ii): Unbalance-over-Limit Index (UoLI)

- Determine rms of UoL for each week

- UoL is the maximum of the weekly values across the survey period. 


\section{B. Harmonics}

A secondary index can be defined for each harmonic. In particular, for THD, we define the Harmonics-over-Limit Index $(\mathrm{HoLI})$ as follows

Step (i): Harmonic-over-Limit (HoL)

Let $\mathrm{THD}_{\max }$ be maximum acceptable THD

If THD $>\mathrm{THD}_{\max }, \mathrm{HoL}=\left(\mathrm{THD}-\mathrm{THD}_{\max }\right)$

If $\mathrm{THD}<\mathrm{THD}_{\min }, \quad \mathrm{HoL}=0$

Step (ii): Harmonic-over-Limit Index (HoLI)

- Find rms of HoL for each week for each phase

- Find a weekly value by taking the maximum across the phases

- Combine across the weeks the maximum of the weekly values

Where only a few harmonics are measured, as in some distribution system surveys there is need for a secondary index that confirms that the measured harmonics are indeed the significant components. For this purpose we define the Harmonics Inclusiveness Index (HII) as follows

- Determine the Harmonic Inclusiveness Value (HIV) for each week for each phase using

$$
\mathrm{HIV}=(95 \% \mathrm{~V} 5) /(95 \% \text { THD })
$$

- Obtain a weekly value by taking the minimum value across the phases

- HII is the minimum of the weekly values across the survey period

Where a larger number of harmonics is measured, it might be desirable to expand the numerator to include them. Unlike other secondary indices proposed above, this index indicates concerns by having too small a.value, since it indicates that measured harmonics are too small to explain the THD value. Since $95 \%$ values are used, it should not be expected that the Hll must always approach unity if more harmonics are included under time-varying conditions because of diversity between the harmonic components.

This index becomes less useful if there are high frequency components having small limit values, since harmonic limits might be exceeded by components not making a major contribution to the THD. In this case, harmonic components might need to be weighted by their limiting value (Normalisation as discussed in Section 2.2) prior to the above calculations. The THD value then needs to be replaced by a weighted THD involving the normalised components. This will require a recording of all harmonic components to the 40th component, giving a several times increase in the size of the $P Q$ database, but fulfilling no real need at present.

\section{Voltage}

The secondary index is called Voltage-Outside-Range : Index or VoRI. We assume a similar model for impact on equipment applies to the index based on Absolute Voltage Deviation. This assumes that equipment is equally unaffected at the maximum and minimum limits of the voltage range and that equal exceedances into the high or low voltage region have similar effects. Again a 2-step process is given.

Step (i): Voltage-outside-Range (VoR)

Let $V_{\max }$ and $V_{\min }$ be maximum and minimum acceptable voltages

$$
\begin{array}{lc}
\text { If } V>V_{\text {max }}, & V o R=\left(V-V_{\max }\right) \\
\text { If } V<V_{\text {min }} & V O R=\left(V_{\min }-V\right) \\
\text { Else } & V o R=0
\end{array}
$$

Step (ii) Voltage-outside-Range Index (VoRl)

- Determine rms for each phase of VoR for each week

- Obtain a weekly value by taking the maximum VoR across all phases

- VoRI is the maximum of the weekly values across the survey period.

D. Sags

A high Sag Index may be due to number of factors, for example

- Protection operation is long

- Site is exposed to a large length of nearby of overhead line

- Overhead line has a large number of faults $/ \mathrm{km}$

The secondary indices to be proposed here are designed to determine which of these factors might be the most important in a particular case.

(I) Protection Index: The discussion here is specifically oriented to distribution systems. It may be adapted to transmission systems when the difference in protection operating times is allowed for

[10] shows that distribution protection settings lead to a relationship between sag retained voltage and duration as shown in Fig. 3. This is called the Protection Curve. Sags to the right of this curve are anomalous - they might be due to direct faults or some type of equipment malfunction. A site with a large proportion of sags to the right of the Protection Curve deserves special investigation. The Protection Index gives a measure of the average amount by which sag durations lie to the right of the protection curve and its definition has been influenced by the definition of the secondary indices for Unbalance-over-limit etc.

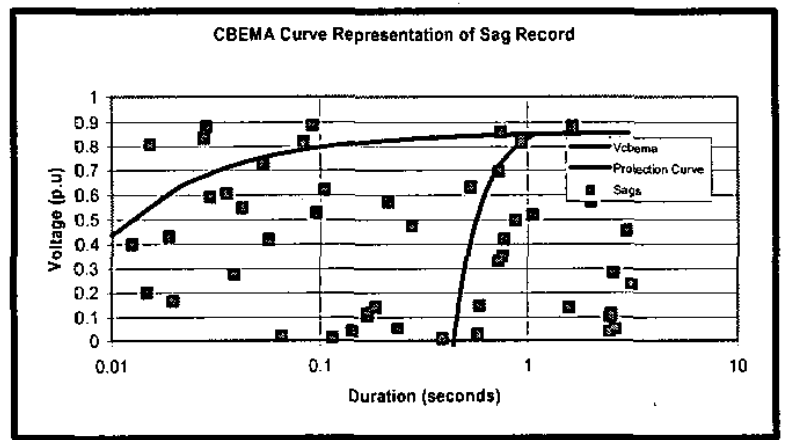

Fig. 3 Sag scattergraph showing CBEMA curve (top left) and Protection curve (right) 
For a reflected fault, the protection operating time $T_{p}$ for many Australian distribution networks is expected to be approximated by

$$
\mathrm{T}_{\mathrm{p}}=2.7 \mathrm{~V}^{9}+0.47
$$

where $V$ is the retained sag voltage in pu and $T_{p}$ the protection operating time is in seconds. The Sag excess Duration (SeD) is determined for each sag with duration $T$ as follows

- If $\mathrm{T}<\mathrm{T}_{\mathrm{p}}$

- $\quad$ If T $>T_{p}$

$$
\mathrm{SeD}=0
$$

$$
\mathrm{SeD}=\mathrm{T}-\mathrm{T}_{\mathbf{p}}
$$

The Protection Index (PI) is given by the rms value of all $\mathrm{SeD}$ values.

(2) Number of Sags: The number of sags has traditionally been used as an indicator of sag activity at a site. A problem a simple count of the number of sags is that the threshold setting of instruments may not be the same at several sites. If there are many sags with voltages of close to $90 \%$, for example due to large motor DOL starts, an inconsistent count will be obtained. It is recommended that this be addressed as for the Sag Severity calculation in [9] by reducing the effective number of sags in the region of sag voltages $80 \%$ to $90 \%$.

For each sag we define Sag Weighting

- If $\mathrm{V}$ is less than 0.8

$$
\text { Sag Weighting }=1
$$

- If $\mathrm{V}$ lies between 0.8 and 0.9

$$
\text { Sag Weighting }=10 *(0.9-\mathrm{V})
$$

The Number of Sags for a site is defined to be the sum of the Sag Weightings over the survey period, scaled to an annual reporting period.

(3) Exposure Index; Let Length be the typical length of nearby overhead lines, including spurs, influencing the annual sag activity at a site. The Exposure index is defined as

$$
\text { Exposure Index }=\text { Sag Count } / \text { Length }
$$

\section{COMPARISON VALUES}

A project has recently commenced in Australia for the long term surveying of power quality levels in distribution systems. At this stage, nine of the sixteen distributors are participating, covering most of the more heavily populated east coast. The first year of the project mainly involved participants putting systems into place. On average, each of the 200 sites provided 6 months data. As well as comparing primary indices with standards, all secondary indices except Exposure Index were determined.

The values given in Table I below are maximum expected values of Primary Indices and are based on standards applied in Australia. The level for MV voltage is only applied to MV substations without Line Drop compensation where tight control can be expected. The harmonic values are taken from [1] but are being reviewed and will be slightly modified in future. The use of the Sag Index is very recent and the value given has to be considered provisional.
TABLE I

MAXIMUM ACCEPTABLEE VALUES ADOPTED FOR PRIMARY INDICES. NOTE COMMENTS REGARDING THE STATUS OF THESE VALUES GIVEN IN THE TEXT

\begin{tabular}{|l|l|l|l|}
\hline Disturbance & \multicolumn{1}{|c|}{ Index } & LV Limit & MV Limit \\
\hline Voltage & $95 \%$ AVD & $6 \%$ & $3 \%$ \\
\hline Unbalance & $95 \%$ VUF & $2 \%$ & $2 \%$ \\
\hline Harmonics & $95 \%$ THD & $8 \%$ & $8 \%$ \\
\hline Sags & Sag Index & 200 & 200 \\
\hline
\end{tabular}

For the Secondary Indices, the values not exceeded by $95 \%$ of sites were determined. Using these as a guide, provisional "alert" values of Secondary indices were determined and listed as shown in Table II. With longer term, more tightly controlled surveying, it is hoped that these values can be further refined so that they become useful internal utility checks of site power quality variations.

$$
\text { TABLE II }
$$

PROVISIONAL "ALERT" VALUES

\begin{tabular}{|l|l|l|}
\hline & \multicolumn{1}{|c|}{ LV } & \multicolumn{1}{c|}{ MV } \\
\hline VoRI & $>3.2 \%$ & $>1.8 \%$ \\
\hline UoLI & $>1.4 \%$ & $>1.5 \%$ \\
\hline HoLI & $>0 \%$ & $>0.5$ \\
\hline HII & $<0.7$ & $<0.8$ \\
\hline PI & $>1 \mathrm{sec}$ & $>1 \mathrm{sec}$ \\
\hline N & $>400$ & $>400$ \\
\hline
\end{tabular}

At low voltage, the voltage can vary up to $\pm 6 \%$ from the middle of the range for $95 \%$ of the time as shown in Table I. The primary index puts no limit on the voltage variations which might occur for the worst $5 \%$ of the time, but a limit is provided by the secondary indices of Table II. Based on the model of customer equipment impact given in Section III, voltage variations are limited to the equivalent of a constant voltage of $3.2 \%$ above the upper voltage limit or $3.2 \%$ below the lower voltage limit. Similar but tighter requirements apply at $\mathrm{MV}$.

A limit of $2 \%$ was adopted for Unbalance at both LV and MV. MV sites show, from the UoLI value in Table II, slightly larger deviation outside the limits. As the LV sites in the survey are predominantly from one state and the MV sites from another, this is not such a surprising result. As we become more systematic and consistent in our monitoring practices, it would be expected that the MV Secondary Index would be less than the LV value. A value of $0.7-0.8$ for HII indicates that the rms value of the unmeasured harmonics is about $90 \%$ of the measured harmonics, with the measured harmonics dominating marginally. It should not be forgotten that the values given in Table II are large enough to cover most sites - many sites had values considerably less.

The Protection Index is similar for LV and MV sites with many sites having sag durations up to 1 second longer than normal protection practices would suggest. A Sag Number of 400 holds at $95 \%$ of sites. A couple of sites exceeded this number by a factor of $2-3$; this is a concern and they will be investigated. 


\section{CONCLUSION}

Primary indices give a direct indication as to whether a site is acceptable according to a specified standard. For Variations, $95 \%$ values over a week can be used, with allowance for different values being found across the phases and where there is more than one week of data. Voltage gives an additional complication which can be resolved by the use of Absolute Voltage Deviation values. A new approach has been proposed for Sags as there is no generally accepted sag standard which can be adapted to site indices. Methods are presently being developed to treat transients in a similar manner.

Secondary indices give additional insights without being directly based on procedures given in standards. For Variations, indices are proposed based on a simple model of damage to customer equipment. An additional index for harmonics characterises the spectrum. The indices proposed for Sags related to the factors affecting sag severity protection operation, the number of sags and the length of exposed line affecting the site.

Indicative acceptable values for most of these quantities have been proposed based on preliminary survey results. It is expected that, with further experience, these values will be refined. Further secondary indices can be expected to be developed with better understanding of the causes and effects of $P Q$ disturbances.

\section{ACKNOWLEDGMENT}

The ESAA (formerly Electricity Supply Association of Australia - now Energy Supply Association of Australia) Power Quality Working Group has strongly encouraged the development of new indices and supported monitoring campaigns to confirm their usefulness. The authors gratefully acknowledge the financial support of Integral Energy and the Australian Research Council SPIRT funding scheme. Acknowledgements also to $\mathrm{Mr}$ Sean Elphick and Chandana Herath for advice and assistance.

\section{REFERENCES}

[1] IEC Standard for Electromagnetic Compatibility (EMC) - part 3: Limits - Section 6: Assessment of Emission Limits for Distorting Loads in MV and $H V$ power Systems, IEC 61000-3-6:1996.

[2] IEC Standard for Electromagnetic Compatibility (EMC) - part 3: Limits - Section 7: Assessment of Emission Limits for Fluctuating Loads in MV and HV power Systems, IEC 61000-3-7:1996.

[3] IEC Standard for Electromagnetic Compatibility (EMC) - part 4-30: Testing and Measurement Techniques - Power quality: Measurement Methods, IEC 61000-4-30:2003.

[4] V.J. Gosbell, H.M.S.C. Herath, B.S.P. Perera, D.A. Robinson,"Sources of Errors in Unbalance Measurements" AUPEC'02 Conference Proceedings, Sept-Oct 2002, Melbourne, Australia, Paper 101.

[5] European Standard for Voltage Characteristics of Electricity Supplied by Public Distribution Systems, CENELEC EN 50160: 1994.

[6] V.J. Gosbell, B.S.P. Perera, H.M.S.C. Herath,"New Framework for Utility Power Quality (PQ) Data Analysis" AUPEC'OI Conference Proceedings, Sept-Oct 2001, Perth, Australia, pp. 577-582.

[7] V.J. Gosbell, A. Baitch, M.H.J. Bollen,"The reporting of Distribution Power quality Surveys" Proceedings of CIGRE/IEEE International Symposium "Quality and Security of Electric Power delivery systems", Oct 2003, Montreal, Canada, paper 204.
[8] M.H.J. Bollen, D.D. Sabin, R.S. Thallam,"Voltage Sag Indices - Recent Developments in IEEE P1564 Task force" Proceedings of CIGRE/IEEE International Symposium "Quality' and Security of Electric Power delivery systems", Oct 2003, Montreal, Canada, paper 202.

[9] V.J. Gosbell, D. Robinson, S. Perera,"The Analysis of Utility Voltage sag data", International Power Quality Conference Proceedings, Oct 2002, Singapore, pp. 479-490.

[10] R. Barr, D. Sweeting, V.J. Gosbell,"New concepts for a Voltage Sag Immunity Standard", EESA Annual Conference, Aug 2003, Sydney, Australia.

\section{BIOGRAPHIES}



Vic Gosbell (M'1972): Dr Gosbell obtained his BE degree in 1966 and his $\mathrm{PhD}$ in 1971 from the University of Sydney. In 1973 he commenced lecturing at the University of Sydney and in 1990 took up the position of Associate Professor at the University of Wollongong where now he is a Professor of Power Engineering and working on power electronic simulation, harmonics and power quality. He is a Fellow of the Institution of Engineers, Australia and a past Chairperson of the Australasian Committee for Power Engineering.

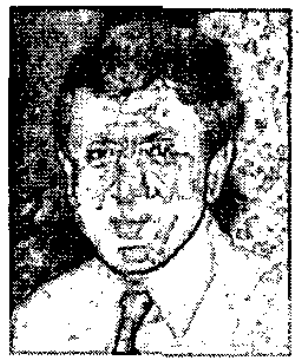

Sarath Perera (M'1988): Dr Perera graduated from the University of Moratuwa, Sri Lanka with a BSc (Eng) degree (1974) specialising in Electrical Power. He obtained his MEngSc degree (1978) from the University of New South Wales and the $\mathrm{PhD}$ degree (1988) from the University of Wollongong. He was an academic at the University of Moratuwa, Sri Lanka for nearly 12 years and is now a Senior Lecturer at the University of Wollongong. His research interests are in Power Quality.

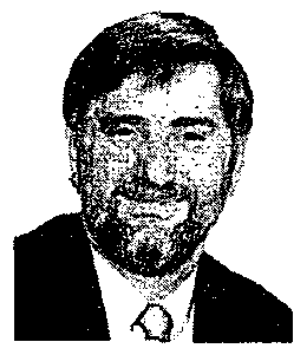

Robert Barr (M'1900): Dr Robert Barr is a consulting engineer and director of his company Electric Power Consulting Pty Lid. Robert holds an Honours degree in Electrical Engineering from Sydney University, a Master of Engineering degree from the University of NSW and a PhD in electrical engineering from the University of Wollongong. Robert has over 30 years experience in the field of electricity distribution and is a fellow of the Institution of Engineers Australia and a member of the Association of Consulting Engineers Australia.

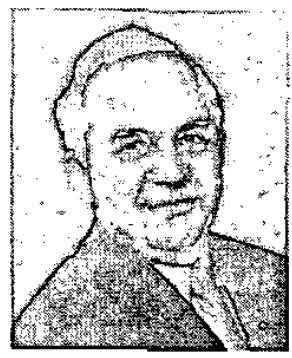

Alex Baitch(M'1984,SM'1993): Mr Baitch is Principal of his own consulting practice BES (Aust) Pty Ltd which he established in 1993. he obtained his BE degree in 1970 from the University of Sydney, MengSc degree in 1974 and MBA(techMgt) in 1995. He has had a wide range of experience in the electrical industry, including close involvement with UPS systems and power quality issues. Alex has been closely jnvolved in standards and professional activities in Australia and internationally. 